\title{
Characterization of botanical origin of selected popular purple Eleutherococcus tea grown in Yunnan province of China and quantification of Its anthocyanins using spectrophotometric method
}

\author{
Yue CHEN ${ }^{1}$, Majie GONG ${ }^{1,2}$, Xianxian $\mathrm{NIE}^{1}$, Zhechen $\mathrm{QI}^{1}$, Xiangqian LIU $^{3}$ (D), Qinghao JIN ${ }^{2}$, Xiaodan ZHANG ${ }^{*}$, \\ Dongfeng YANG ${ }^{*}$
}

\begin{abstract}
Purple Eleutherococcus is a selected plant grown in high mountain in Puer region of Yunnan province, which is a rich source of anthocyanins with great potential as local vegetables and tea. However, the unknown botanical origin of purple Eleutherococcus restricted its edible value. Our objectives were to identify the botanical origin of purple Eleutherococcus by DNA marker combined with the morphological characteristics, optimaze the extration method of anthocyanins by orthogonal experiment method and determine the contents of anthocyanins in purple Eleutherococcus tea. The results revealed that the purple Eleutherococcus was more closely related to Eleutherococcus simonii through comparing the sequence alignment of ITS2. Combined with the morphological characteristics of plants, purple Eleutherococcus was finally identified and classified into Eleutherococcus simonii. Through orthogonal experiment, the optimal extraction conditions of anthocyanins from purple Eleutherococcus leaves were determined: the volume fraction of ethanol was $60 \%$, the $\mathrm{pH}$ of ethanol solution was 3 , and the water bath temperature was $60^{\circ} \mathrm{C}$. The ultrasonic extraction was conducted for $30 \mathrm{~min}$. Our study provides scientific theoretical basis for the industrial extraction of anthocyanins and provides reference value for the further development of purple Eleutherococcus in Puer region of Yunnan province in China.
\end{abstract}

Keywords: purple Eleutherococcus; botanical identification; extraction optimazation; determination of anthocyanins.

Practical Application: Origin of purple Eleutherococcus tea and quantification of its anthocyanins.

\section{Introduction}

As a perennial shrub plant, purple Eleutherococcus had a light violet stem and spherical fruit with special aroma, which was mainly distributed in Puer region of Yunnan province and southeast Asia. Its characteristic of the tender tip was purple, sweet aftertaste and no bitter taste (Li et al., 2016). As well known, Eleutherococcus plants have anti-inflammatory, anti-rheumatism, anti-arrhythmia, tonic and other medicinal value (Zhao et al., 2014). In addition, the purple Eleutherococcus can improve the quality of sleep, benefit vital energy, tonify spleen and relieve mental strain (Wang et al., 2018). Through related content determination, purple Eleutherococcus was rich in amino acids, crude fiber, vitamin C and minerals (Zhao et al., 2014). Previous study had shown that purple Eleutherococcus was considered as Eleutherococcus senticosus (Rupr. et Maxim.) Maxim. However, morphologically characteristic (Figure 1) showed purple Eleutherococcus had branches glabrous, usually with a coarsely recurved spine, while Eleutherococcus senticosus had branches with dense to scattered, slensder, terete, bristlelike prichles (http:// www.iplant.cn/frps) (Zhai et al., 2017). Therefore, the origin of purple Eleutherococcus still needs to be further determined.
Anthocyanins was a class of water-soluble natural pigment that widely present in plants which belongs to flavonoids (Harakotr et al., 2015; Timberlake \& Bridle, 1977). The leaves and stem bark of purple Eleutherococcus was pale purple, which contained large amounts of anthocyanins. At the same time, anthocyanins were also dozens of times of Eleutherococcus senticosus. The complex contents of saccharides, sugar alcohol, organic acids, amino acids, proteins, and other components in purple Eleutherococcus affects the stability of anthocyanins, and its liquid viscosity was relatively high, resulting in difficulty in concentration and drying (Abdel-Aal et al., 2014; Fuleki \& Francis, 1968). Therefore, it is necessary to study the method of extracting and purifying anthocyanins from purple Eleutherococcus.

To reach our objectives, we compared the ITS2 sequence of purple Eleutherococcus with other known Eleutherococcus species identified by Yook Changsoo professor (Liu et al., 2015), and combining with the plant morphological characteristic analysis to determine the origin of purple Eleutherococcus (Bae et al., 2001; Park et al., 2005). In addition, anthocyanins were extracted from the purple Eleutherococcus tea by ultrasonic-assisted

${ }^{1}$ Key Laboratory of Plant Secondary Metabolism and Regulation, College of Life Sciences and Medicine, Zhejiang Sci-Tech University, Xiasha Higher Education Zone, 

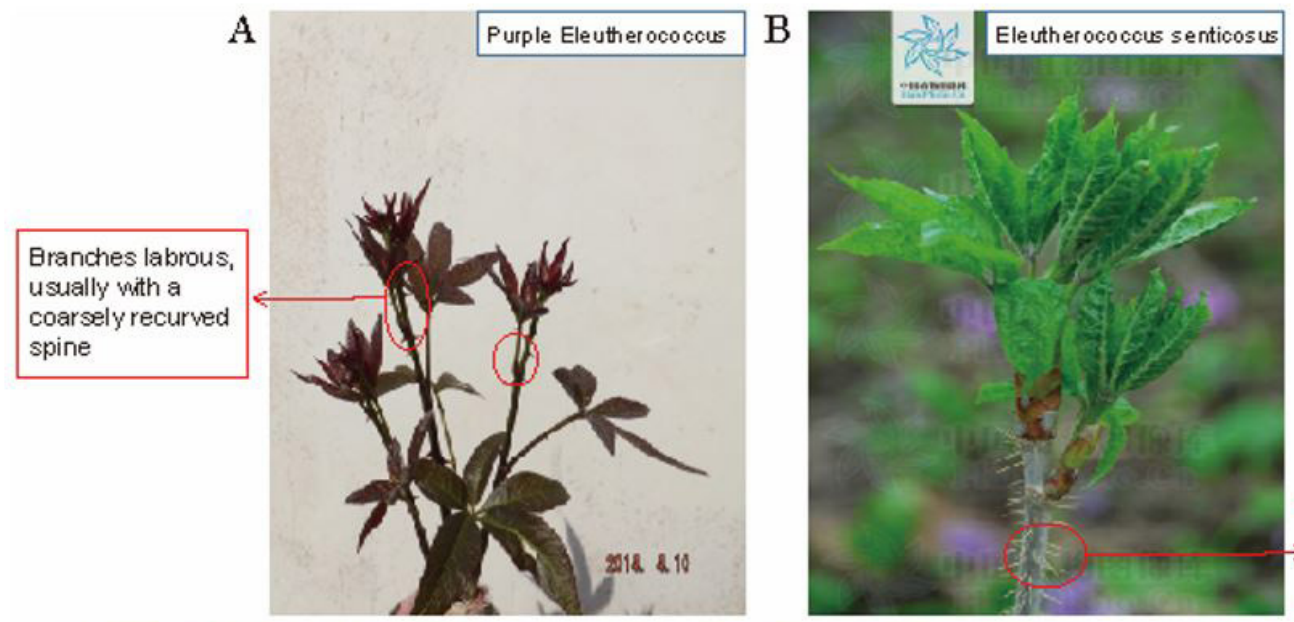

Branches with dense to scattered slensder, terete, bristlelike prichles
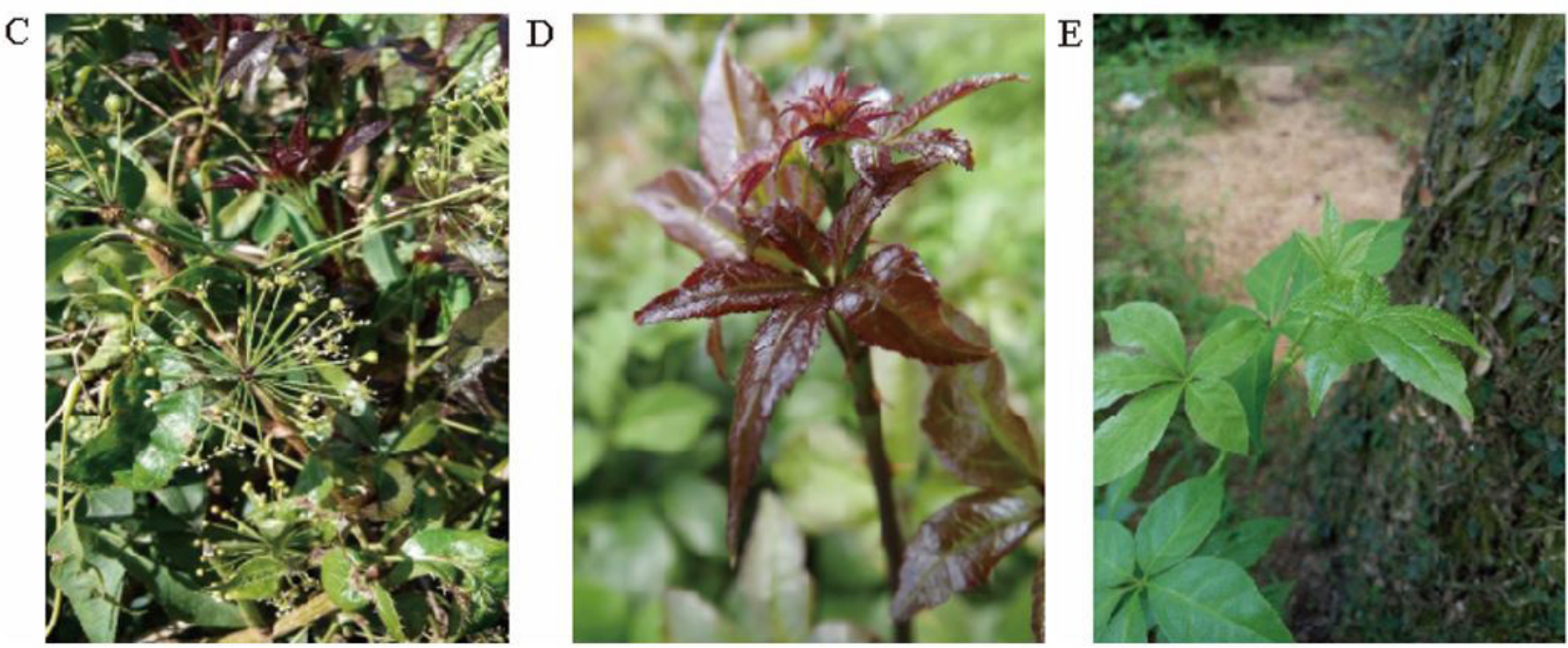

Figure 1. A: Flowers and leaves of purple Eleutherococcus. B: Leaves of Eleutherococcus simonii. C: Flowers of purple-Eleutherococcus. D: Leaves of purple-Eleutherococcus. E: Leaves of Eleutherococcus trifoliatus (Linn.) Merr. var. setosus Li.

acidification (Jiang et al., 2017). The effective extract conditions of anthocyanins were determined by establishing orthogonal table and related validation experiments (Hiranrangsee et al., 2016). Our study provides a scientific theoretical basis for the industrial extraction of anthocyanins and provides a reference value for the further development of the medicinal value of anthocyanins from the purple Eleutherococcus.

\section{Materials and methods}

\subsection{Samples}

Four species of Eleutherococcus samples (Eleutherococcus trifoliatus (Linn.) Merr. var. trifoliatus, Eleutherococcus gracilistylus, Eleutherococcus simonii, Eleutherococcus trifoliatus (Linn.) Merr. var. setosus $\mathrm{Li}$ ). were kindly provided by the Wuhan Botanical Garden of the Chinese Academy of Sciences and identified by Yook Changsoo professor (Liu et al., 2015). Eleutherococcus koreanum Nakai was provided by Medicinal botanical garden of
KyungHee University in South Korea. Purple Eleutherococcus was sampled from Puer region of Yunnan province, China. All Chemicals were purchased from Hangzhou Gaojing Fine Chemical (Hangzhou Gaojing Fine Chemical Co., Ltd, Hangzhou, Zhejiang, China).

\subsection{DNA marker identification of purple Eleutherococcus}

Total genomic DNA was extracted from single individuals using cetyltrimethylammonium ammonium bromide (CTAB method). The nuclear rDNA fragment that included part of the 5.8S rDNA gene, the second internal transcribed spacer (ITS2), and part of the 28S rDNA gene was amplified by PCR. Amplification was performed in a T100 $0^{\text {mit }}$ Thermal Cycle (Bio-Rad Laboratories, Inc. Hercules, California, USA). The reaction mixture (DNA, PCR Forward Primer,PCR Reverse Primer, $\mathrm{ddH}_{2} \mathrm{O}, \mathrm{PCR}$ mix), using ITS2F,ITS3R (Supplementary Table 1) as primers, and temperature profiles $\left(94^{\circ} \mathrm{C} 30 \mathrm{~s}, 56^{\circ} \mathrm{C} 30 \mathrm{~s}, 72^{\circ} \mathrm{C} 45 \mathrm{~s}\right.$ for 35 cycle) used in amplification of nuclear spacer fragment. The amplification products were separated by electrophoresis 
purchased from Tanon (Tanon Science \& Technology Co., Ltd. Shanghai, China) on a $1 \%$ agarose gel in 1 TAE buffer in the presence of Gel imager (Tanon Science \& Technology Co., Ltd.) and photographed. The obtained PCR products were purified using a Biosilicareagent kit and sequence by using forward and reversed primers on an ABI 3130xl automated sequencer (Thermo Fisher Scientific Inc. Waltham, MA, USA) at the (http:// sequest.niboch.nsc.ru).

\subsection{Ultrasonic-assisted extraction}

Five of the $1.00 \mathrm{~g}$ of purple Eleutherococcus tea powder samples were mixed with $40 \mathrm{~mL}$ of $60 \%$ ethanol, and the mixture was directly sonicated in the ultrasonic extraction tank (Kun Shan Ultrasonic Instruments Co., Ltd Jiangsu, China) for $30 \mathrm{~min}$ at $40^{\circ} \mathrm{C}$ and at a frequency of $50 \mathrm{kHz}$. After extraction, suction filtration (by centrifuge for $10 \mathrm{~min}$ ) was used to obtain the filtrate. The supernatant of $100 \mathrm{~mL}$ was absorbed with locomotive pipette (Eppendorf AG, Inc., Hamburg, Germany), diluted to $1 \mathrm{~mL}$ with two prepared buffers, and Abs was measured with enzyme-labeled instrument (BioTek Instruments, Inc. Winooski, VT, USA) at dual wavelengths $(510 \mathrm{~nm}$ and $700 \mathrm{~nm}$ ). The anthocyanins yield was estimated according to the method of " 2.5 ". Measurements were done in triplicate and take the average.

\subsection{Optimization of ultrasonic-assisted extraction condition}

Firstly, the effects of ethanol concentration (50\% to $90 \%$ $\mathrm{v} / \mathrm{v})$, extraction time (20 to $60 \mathrm{~min}$ ), extraction temperature $\left(30\right.$ to $70^{\circ} \mathrm{C}$ ) and $\mathrm{pH}$ of solvent $(1.5,2,2.5,3,3.5 \mathrm{~mL} / \mathrm{g}$ ) on the extraction yield of anthocyanins from purple Eleutherococcus tea powder were investigated. Secondly, an orthogonal test was designed to optimize the extraction parameters (factors) depending on the results of the above single factor experiments. The factors and levels tested in this study are presented in Table 1. The orthogonal test design consisted of nine separate experiments (Table 2). The sequence in which the experiments were performed and randomized to ensure the validity of the test results. In this study, all the experiments were performed in triplicate and IBM SPSS Statistics 20.0 was used to analyze the data in this study.

\subsection{Quantification of its anthocyanins using spectrophotometric method}

Use locomotive pipette to absorb $100 \mathrm{~mL}$ of liquid. Dilute the hydrochloric acid-sodium chloride buffer solution and acetic acid-sodium acetate buffer solution to $1 \mathrm{~mL}$ and mix them thoroughly. Using a 96-well plate added to each sample $200 \mathrm{~mL}$ into three walls for each mixed sample. Abs was measured at double wavelengths ( $510 \mathrm{~nm}$ and $700 \mathrm{~nm}$ ) with an enzyme-labeled instrument (BioTek Instruments, Inc.) (correction optical path difference was $1 \mathrm{~cm}$ ). We referred the method from Professor Wang Y (Ravanfar et al., 2015; Wang et al., 2016) and made appropriate improvements. The anthocyanins content of each sample solution was calculated using the Equation 1 below:

Total anthocyanins $(\mathrm{mg} / \mathrm{g})=(\mathrm{A} \times \mathrm{Mt} \times \mathrm{DF} \times \mathrm{V}) /(\mathrm{e} \times \mathrm{b} \times \mathrm{m})$

$A=\left\{\left(A_{510}-A_{700}\right)_{p H 1.0}-\left(A_{510}-A_{700}\right)_{p H 4.5}\right\}$

where

A Absorbance of sample at $510 \mathrm{~nm}$ and $700 \mathrm{~nm}$

Table 1. Orthogonal experimental factors and levels.

\begin{tabular}{ccccc}
\hline Levels & $\begin{array}{c}\text { A. Ethanol volume fraction } \\
(\%)\end{array}$ & B. pH & $\begin{array}{c}\text { C. Ultrasonic extraction } \\
\text { bath temperature }\left({ }^{\circ} \mathrm{C}\right)\end{array}$ & $\begin{array}{c}\text { D. Ultrasonic extraction } \\
\text { time }(\mathrm{min})\end{array}$ \\
\hline 1 & 50 & 2.5 & 50 & 30 \\
2 & 60 & 3 & 60 & 40 \\
3 & 70 & 3.5 & 70 & 50 \\
\hline
\end{tabular}

Table 2. Orthogonal experimental results.

\begin{tabular}{|c|c|c|c|c|c|}
\hline Number & $\begin{array}{l}\text { A. Ethanol volume } \\
\text { fraction (\%) }\end{array}$ & B. $\mathrm{pH}$ & $\begin{array}{c}\text { C. Ultrasonic } \\
\text { extraction bath } \\
\text { temperature }\left({ }^{\circ} \mathrm{C}\right)\end{array}$ & $\begin{array}{c}\text { D. Ultrasonic } \\
\text { extraction time (min) }\end{array}$ & $\begin{array}{l}\text { E. Anthocyanin } \\
\text { content }(\mathrm{mg} / \mathrm{g})\end{array}$ \\
\hline 1 & 1 & 1 & 1 & 1 & 0.494 \\
\hline 3 & 1 & 3 & 3 & 3 & 0.334 \\
\hline 4 & 2 & 1 & 2 & 3 & 1.015 \\
\hline 7 & 3 & 1 & 3 & 2 & 0.975 \\
\hline 8 & 3 & 2 & 1 & 3 & 0.928 \\
\hline 9 & 3 & 3 & 2 & 1 & 1.069 \\
\hline K1 & 0.519 & 0.828 & 0.873 & 1.013 & \\
\hline K2 & 1.229 & 1.044 & 0.937 & 0.966 & \\
\hline
\end{tabular}


Mt Relative molecular mass of Cyanidin-3-glucoside-449.2

DF Dilution factor

$\mathrm{V}$ The known volume anthocyanins extract was made up to after extraction $(m L)$

e Extinction coefficient of Cyanidin-3-glucoside-26900

b Optical path difference $(\mathrm{cm})^{-1} \mathrm{~cm}$

$\mathrm{m}$ The weight of purple Eleutherococcus Senticosus tea powder for extraction $(g)$

\section{Results and discussion}

\subsection{Origin identified of purple Eleutherococcus source by DNA molecular marker}

We extracted the DNA of eight species of Eleutherococcus (Eleutherococcus trifoliatus (Linn.) Merr. var. trifoliatus, Eleutherococcus gracilistylus, Eleutherococcus simonii, Eleutherococcus trifoliatus (Linn.) Merr. var. setosus Li, and Eleutherococcus koreanum Nakai.). Using ITS2F and ITS3R as amplification primers and comparing with 2000 DNA Marker, it was found that there were obvious amplification bands around 500 bp (Figure 2).

Selected the following procedures according to the company's sequencing results. Use geneious 10 software for the de novo connection and alignment. K3P model was selected to constructed Iqtree (Nguyen et al., 2015; Trifinopoulos et al., 2016). Boehmeria gracilis $\mathrm{C} . \mathrm{H}$. Wright and Macropanax rosthornii (Harms) C. $\mathrm{Y}$. Wu ex Hoo were selected as the outer group. The composition of PCR amplification products was analyzed, and the sequences at both ends of the amplification products were removed. Use Treegraph software to modify and view the phylogenetic tree (Figure 2) (Müller \& Müller, 2004). The ITS2 sequences of each sample were obtained and uploaded to GenBank. The different Eleutherococcus samples of each species were first grouped into one branch. On this basis, Eleutherococcus simonii and Purple Eleutherococcus were clustered as one branch, and then together with Eleutherococcus trifoliatus (Linn.) Merr. var. setosus $\mathrm{Li}$ were clustered as one branch, indicating that these three Eleutherococcus were closely related. The ITS2 sequence of No.1-6 purple Eleutherococcus samples were identical, with a sequence length of $433 \mathrm{bp}$. The homology of purple Eleutherococcus

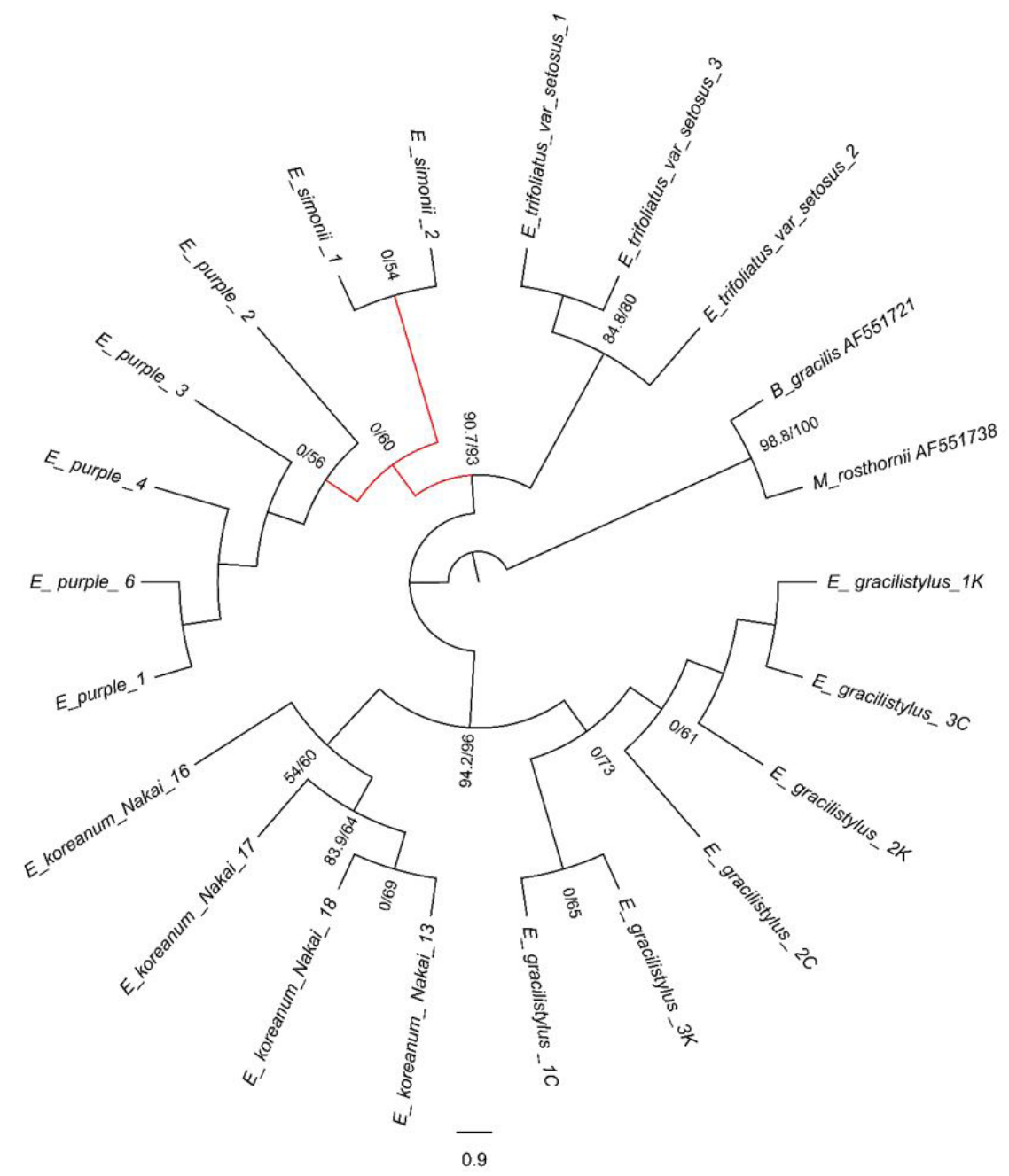

Figure 2. Phylogenetic tree of purple Eleutherococcus compared with other Eleutherococcus plants. 
(No. 1-6) and the corresponding sequence of Eleutherococcus simonii in GenBank (No: GQ434775) was 100\% identical.

We observed and compared the leaves and flowers of purple Eleutherococcus, there were 5-loculeds of the ovary, when it is fruiting the stigma lobes are separated with the styles united into columns. The umbel forms a compound umbel with longer petiole, strong and curved branches. Leaf blade of purple Eleutherococcus was larger with densely setae on bilateral veins, doubly serrate of margin. The morphological feature was similar to Eleutherococcus simonii (Figure 1). Meanwhile, with the phylogenetic relationship analysis of phylogenetic trees, we classified purple Eleutherococcus as Eleutherococcus simonii.

\subsection{Optimize extraction of anthocyanins in purple Eleutherococcus tea by orthogonal experimental method}

\section{Ethanol volume fraction}

Pictures was drawn by Graph Pad Prism 6 software (Graph Pad Software Inc, CA). As shown in Figure 3A, the anthocyanins yield increases first when the ethanol concentration changes from $50 \%$ to $60 \%(\mathrm{v} / \mathrm{v})$ and goes down when the ethanol concentration is above $60 \%$. When the volume fraction of ethanol above $60 \%$, some impurities will also be extracted, affecting the dissolution of anthocyanins and the final determination of anthocyanins content. Therefore, the optimal ethanol volume fraction determined as $60 \%$.

\section{pH in ethanol solution}

In Figure 3B, when $\mathrm{pH}$ increased from 2 to 3, anthocyanins yield increased with the increase of $\mathrm{pH}$ of the extracted solution. When $\mathrm{pH}$ was 3 , anthocyanins yield reached the maximum value, which was $1.335 \mathrm{mg} / \mathrm{g}$. Anthocyanins contain phenolic hydroxyl groups, which are more water-soluble. When the acidity is too strong, the hydrogen bond formed between the phenolic hydroxyl group and the water molecule is easy to break, thus affecting the solubility of anthocyanins and reducing the extracted anthocyanins. When the acidity is relative weak, anthocyanins change to the colorless chalcone form, reducing anthocyanins content. Therefore, the most moderate $\mathrm{pH}$ determined to be 3 .

\section{Ultrasonic extraction temperature}

The Figure $3 \mathrm{C}$ reflects the trends that the temperature rises from $30{ }^{\circ} \mathrm{C}$ to $60{ }^{\circ} \mathrm{C}$, the yield of anthocyanins increased from $1.303 \mathrm{mg} / \mathrm{g}$ to $1.798 \mathrm{mg} / \mathrm{g}$, and with the continued rise
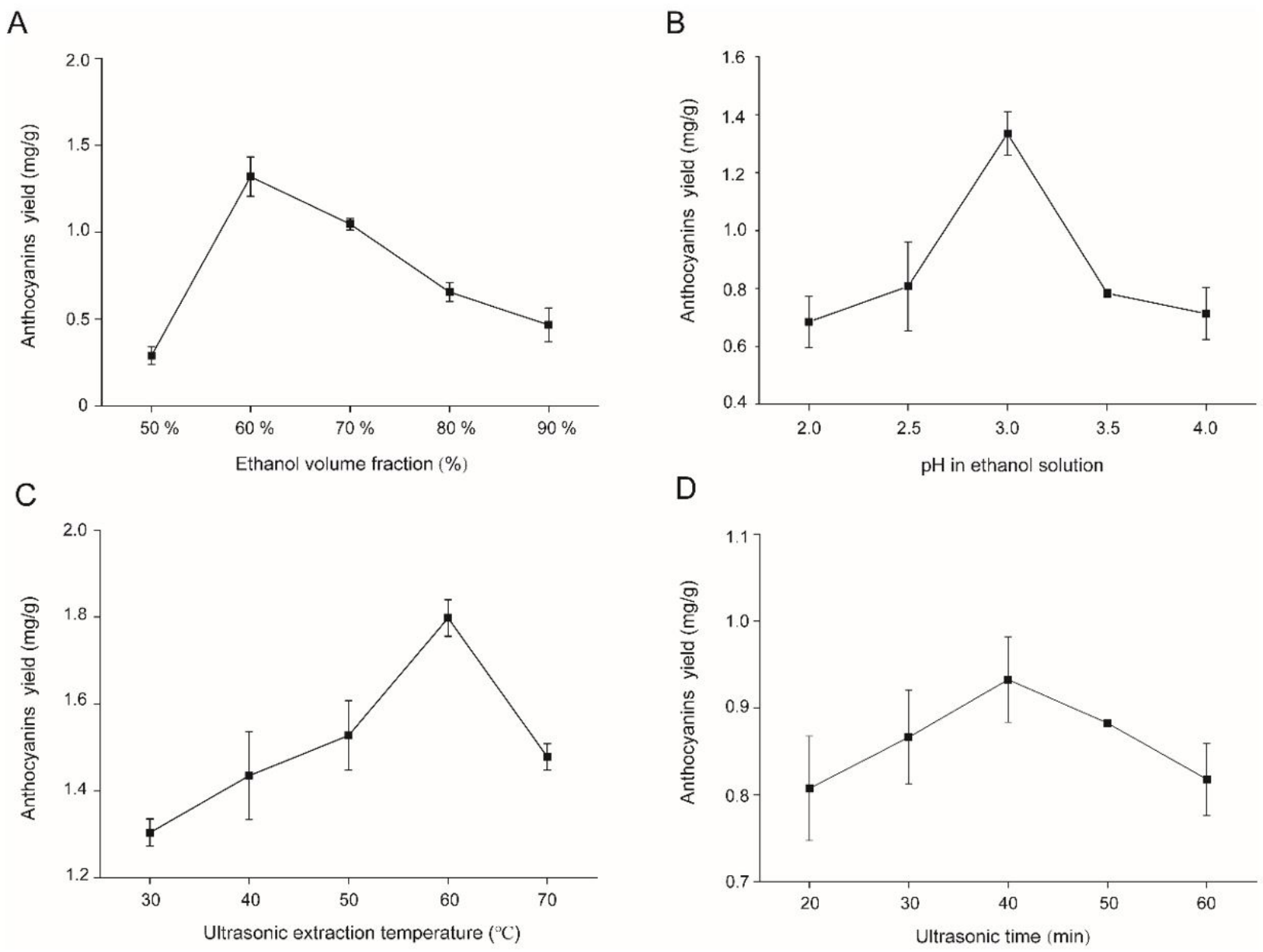

Figure 3. The line chart of ultrasonic-assisted extraction affected the anthocyanin content of each sample. 
Table 3. Verification test results.

\begin{tabular}{ccccc}
\hline Number & Abs & $\begin{array}{c}\text { Anthocyanin content } \\
(\mathrm{mg} / \mathrm{g})\end{array}$ & Average $(\mathrm{mg} / \mathrm{g})$ & $\mathrm{RSD}$ \\
\hline 1 & 0.276 & 1.844 & 1.797 & \\
2 & 0.265 & 1.770 & & \\
3 & 0.266 & 1.777 & & \\
\hline
\end{tabular}

of temperature the yield inversely decreased. The temperature affects the random motion of molecules, the rising temperature accelerates the dissolution rate, and more anthocyanins dissolved. Moreover, high temperature damage the chemical structure of anthocyanins, reducing the active components, leading to oxidation and degradation phenomenon. Therefore, the optimal ultrasonic extraction temperature determined under the experimental conditions is $60^{\circ} \mathrm{C}$.

\section{Ultrasonic time}

The effects of the ultrasonic time on the extraction yield of anthocyanins from purple Eleutherococcus tea were investigated. The results are shown in Figure 3D. The yields significantly increased when the extraction time increased from 20 to $40 \mathrm{~min}$ and then decreased from 40 to $60 \mathrm{~min}$. A longer extraction time indicated a positive effect on the extraction yield, but the yield increased slightly. This phenomenon may be due to the active ingredients will not be dissolved when the solubility of dissolvingout substances became saturate $40 \mathrm{~min}$ with the increase of extraction time, while the loss of anthocyanins was increased with the viscosity of extracts increased when extraction time increased. Therefore, in view of time consumption, extraction time ought not to exceed $40 \mathrm{~min}$.

\section{Orthogonal experimental method}

Through the establishment of orthogonal table and the relevant experiments, we found that the influence of four single factors on the anthocyanins content of each sample in purple Eleutherococcus was quite different manifest as follows: ethanol volume fraction $>$ ultrasonic time $>\mathrm{pH}>$ water bath temperature, which the influence degree of $\mathrm{pH}$ and ultrasonic time is similar. In this study, the best combination to extract anthocyanins from purple Eleutherococcus was determined as A2B2C2D1.

Moreover, the orthogonal experiment was carried out as Table 2 to verify the content of anthocyanins in purple Eleutherococcus tea. Table 3 shows that the content of anthocyanins in the validation test is higher than that in the extraction scheme designed by orthogonal test, which indicates that the optimal extraction technology obtained by orthogonal test is feasible. The results obtained have a small standard deviation and high precision with three repeats.

\section{Conclusion}

In this study, DNA molecular marker technology was performed to determine the origin of purple Eleutherococcus, combining the morphological characteristics of plants. As a result, the species of purple Eleutherococcus was identified and classified as Eleutherococcus simonii. The application of DNA marker identification provides technical support for the development of Chinese medicine identification and makes an important contribution to complete the Flora of China.

Anthocyanins of purple Eleutherococcus was a class of water-soluble natural pigment in plants belongs to flavonoids. The toxicity and economic benefits of the solvent should be considered in the experimental process, ethanol was chosen as the extraction solvent. The efficiency of the experiment was greatly improved because the enzyme-labeled instrument could simultaneously measure the two wavelengths. This method was more rapid and accurate in measurement, providing reference for the determination of anthocyanins.

Through relevant tests, we found that $60 \%$ ethanol had the best extraction effect on anthocyanins with the best permeability and least impurities under such conditions. According to relevant literatures, we found $\mathrm{pH}=3$ is the mildest acidity to extract anthocyanins, $\mathrm{pH}$ breaks the balance between the four structures of anthocyanins, making them transform into each other. As temperature influences effective components of anthocyanins by affecting the stability of anthocyanins, $60{ }^{\circ} \mathrm{C}$ is the optimal extraction temperature of extract anthocyanins. The optimal ultrasonic time determined by the experiment was 40 min which affecting the oxidation ability of anthocyanins. In conclusion the optimal technology to extracted anthocyanins from purple Eleutherococcus as follows: $60 \%$ ethanol volume fraction, $\mathrm{pH} 3,60^{\circ} \mathrm{C}$ for ultrasonic extraction and water bath temperature, $30 \mathrm{~min}$ for ultrasonic extraction time. The content of anthocyanins from purple Eleutherococcus is $1.797 \mathrm{mg} / \mathrm{g}$, which was much higher than $935.14 \mu \mathrm{g} / \mathrm{g}$ that Jin-wen Liu (Liu et al., 2015) extracted anthocyanins from Eleutherococcus senticosus fruit. Therefore, we speculated that purple Eleutherococcus had higher contents of anthocyanins, which indicated greater underlying application for medical and food industry.

\section{Conflict of interest}

There are no conflicts of interest to declare.

\section{Author contributions}

Xiaodan Zhang and Dongfeng Yang designed the study and interpreted the results. Yue Chen collected test data, drew diagrams and drafted the manuscript. Majie Gong, Xianxian Nie and Yue Chen cooperatively completed the experiments in this study. Zhechen Qi assembled ITS2 sequence and constructed Iqtree. Xiangqian Liu and Qinghao Jin sampled Eleutherococcus samples. 


\section{Acknowledgements}

This work was financially supported by the Zhejiang Provincial Natural Science Foundation of China (LR21H280002), Key project at central government level: The ability establishment of sustainable use for valuable Chinese medicine resources (2060302), and Natural Science Foundation of Hunan Province (2019JJ40223).

\section{References}

Abdel-Aal, S. M., Akhtar, H., Rabalski, I., \& Bryan, M. (2014). Accelerated, microwave-assisted, and conventional solvent extraction methods affect anthocyanin composition from colored grains. Journal of Food Science, 79(2), C138-C146. http://dx.doi.org/10.1111/17503841.12346. PMid:24547694.

Bae, E. A., Yook, C. S., Oh, O. J., Chang, S. Y., Nohara, T., \& Kim, D. H. (2001). Metabolism of chiisanoside from Acanthopanax divaricatus var. albeofructus by human intestinal bacteria and its relation to some biological activities. Biological \& Pharmaceutical Bulletin, 24(5), 582-585. http://dx.doi.org/10.1248/bpb.24.582. PMid:11379786.

Fuleki, T., \& Francis, F. J. (1968). Quantitative methods for anthocyanins. Journal of Food Science, 33(1), 72-77. http://dx.doi. org/10.1111/j.1365-2621.1968.tb00887.x.

Harakotr, B., Suriharn, B., Scott, M. P., \& Lertrat, K. (2015). Genotypic variability in anthocyanins, total phenolics, and antioxidant activity among diverse waxy corn germplasm. Euphytica, 203(2), 237-248. http://dx.doi.org/10.1007/s10681-014-1240-z.

Hiranrangsee, L., Kumaree, K. K., Sadiq, M. B., \& Anal, A. K. (2016). Extraction of anthocyanins from pericarp and lipids from seeds of mangosteen (Garcinia mangostana L.) by Ultrasound-Assisted Extraction (UAE) and evaluation of pericarp extract enriched functional ice-cream. Journal of Food Science and Technology, 53(10), 3806-3813. http://dx.doi.org/10.1007/s13197-016-2368-8. PMid:28017996.

Jiang, H. L., Yang, J. L., \& Shi, Y. P. (2017). Optimization of ultrasonic cell grinder extraction of anthocyanins from blueberry using response surface methodology. Ultrasonics Sonochemistry, 34, 325-331. http:// dx.doi.org/10.1016/j.ultsonch.2016.06.003. PMid:27773253.

Li, T., Ferns, K., Yan, Z. Q., Yin, S. Y., Kou, J. J., Li, D., Zeng, Z., Yin, L., Wang, X., Bao, H.-X., Zhou, Y. J., Li, Q. H., Zhao, Z. Y., Liu, H., \& Liu, S. L. (2016). Acanthopanax senticosus: photochemistry and anticancer potential. The American Journal of Chinese Medicine, 44(8), 1543-1558. http://dx.doi.org/10.1142/S0192415X16500865. PMid:27852123.

Liu, H., Guo, J., Li, Z., Zhang, X., Liu, X., \& Yook, C. (2015). Development of chemical fingerprints for quality control of Xiong Ma Tang and its related preparations by high-performance liquid chromatography.
Journal of Chromatographic Science, 54(2), 206-215. http://dx.doi. org/10.1093/chromsci/bmv134. PMid:26472809.

Müller, J., \& Müller, K. A. I. (2004). Treegraph: automated drawing of complex tree figures using an extensible tree description format. Molecular Ecology Notes, 4(4), 786-788. http://dx.doi.org/10.1111/ j.1471-8286.2004.00813.x.

Nguyen, L.-T., Schmidt, H. A., Von Haeseler, A., \& Minh, B. Q. (2015). IQ-TREE: a fast and effective stochastic algorithm for estimating maximum-likelihood phylogenies. Molecular Biology and Evolution, 32(1), 268-274. http://dx.doi.org/10.1093/molbev/ msu300. PMid:25371430.

Park, S. Y., Choi, H. S., Yook, C. S., \& Nohara, T. (2005). A new lupane glycoside from the leaves of Acanthopanax koreanum. Chemical \& Pharmaceutical Bulletin, 53(1), 97-99. http://dx.doi.org/10.1248/ cpb.53.97. PMid:15635239.

Ravanfar, R., Tamadon, A. M., \& Niakousari, M. (2015). Optimization of ultrasound assisted extraction of anthocyanins from red cabbage using Taguchi design method. Journal of Food Science and Technology, 52(12), 8140-8147. http://dx.doi.org/10.1007/s13197-015-1880-6. PMid:26604387.

Timberlake, C. F., \& Bridle, P. (1977). Anthocyanins: colour augmentation with catechin and acetaldehyde. Journal of the Science of Food and Agriculture, 28(6), 539-544. http://dx.doi.org/10.1002/jsfa.2740280611. PMid:881788.

Trifinopoulos, J., Nguyen, L.-T., Von Haeseler, A., \& Minh, B. Q. (2016). W-IQ-TREE: a fast online phylogenetic tool for maximum likelihood analysis. Nucleic Acids Research, 44(W1), W232-W235. http://dx.doi.org/10.1093/nar/gkw256. PMid:27084950.

Wang, Y., Wang, R., Shi, L., Liu, S., Liu, Z., Song, F., \& Liu, Z. (2018). Systematic studies on the in vivo substance basis and the pharmacological mechanism of Acanthopanax Senticosus Harms leaves by UPLC-Q-TOF-MS coupled with a target-network method. Food \& Function, 9(12), 6555-6565. http://dx.doi.org/10.1039/ C8FO01645C. PMid:30484473.

Wang, Y., Zhu, J., Meng, X., Liu, S., Mu, J., \& Ning, C. (2016). Comparison of polyphenol, anthocyanin and antioxidant capacity in four varieties of Lonicera caerulea berry extracts. Food Chemistry, 197(PtA), 522-529.

Zhai, C., Wang, M., Raman, V., Rehman, J. U., Meng, Y., Zhao, J., Avula, B., Wang, Y.-H., Tian, Z., \& Khan, I. A. (2017). Eleutherococcus senticosus (Araliaceae) leaf morpho-anatomy, essential oil composition, and its biological activity against Aedes aegypti (Diptera: Culicidae). Journal of Medical Entomology, 54(3), 658-669. http://dx.doi.org/10.1093/ jme/tjw221. PMid:28399215.

Zhao, L., An, Q., Qin, F., \& Xiong, Z. (2014). Simultaneous determination of six constituents in the fruit of Acanthopanax sessiliflorus (Rupr. et Maxim.) Seem. by HPLC-UV. Natural Product Research, 28(7), 500-502. http://dx.doi.org/10.1080/14786419.2013.877904 . PMid:24438013. 


\section{Supplementary Material}

Supplementary material accompanies this paper.

Supplementary Table 1 Sequencing primer.

Supplementary Table 2 Submitted Genebank ID.

This material is available as part of the online article from https://www.scielo.br/j/CTA 